\title{
Fuzzy logic memprediksi tingkat kecelakaan kerja pada PT Galang Kapal di kota Batam
}

\author{
Sestri Novia Rizki \\ Program studi Teknik Informatika, Fakultas Teknik, Universitas Putera Batam \\ Email: noviasestri@gmail.com
}

\begin{abstract}
Abstrak
Permasalahan yang sering terjadi saat ini adalah kecelakaan kerja pada PT galang kapal. Faktor penyebab kecelakaan seperti, Kelalaian manusia, Peralatan yang digunkanan serta system manajeman yang diterapkan dalam proses kerja, Contoh kecelakaan kerja dari beberapa sumber Koran dan berita di kota Batam yaitu terbakar di dalam kapal,tertimpa besi berat dan wajah melepuh terkena minyak kapal. Tujuan penelitian adalah memprediksi kecelakaan kerja, memperkecil resiko kecelakaan kerja dan Cara mengantisipasi kecelakaan kerja. Medode Mamdani merupakan cara yang tepat dalam memprediksi kecelakaan kerja. Langkah kerja metode mamdani, pertama menentukan fuzification, mesin iferensi dan nilai hasil akhir berupa nilai output Hinggan menghasilkan keputusan dalam memprediksi kecelakaan kerja. Batasan dan cakupan penelitian ini 1. Memprediksi tingkat kecelakaan kerja. 2.Kriteria penyebab kecelakaan kerja 3.Menggunakan metode Mamdani dan Implementasikan menggunakan Software Matlab. Manfaat penelitian mengurangi resiko kecelakaan kerja,
\end{abstract}

Kata kunci: Logika fuzzy, Metode Mamdani, Defuzifikasi

\begin{abstract}
The problem that often occurs today is a work accident at Shipyard Companies. Factors causing accidents such as human negligence, equipment used and management systems applied in the work process. Shipyard The examples of work accidents from several newspapers and news sources in Batam are burning inside the ship, hit by heavy iron and blistered faces exposed to ship oil. Therefore, the objective of this research is how to predict work accidents, minimize the risk of workplace accidents and how to anticipate workplace accidents. Moreover, Mamdani method is the right way to predict work accidents. The step ofMamdani method; first determinefuzzification, the efficiency of machine and the final value in the form of output values until it produces a decision in predicting work accidents. Limitation and scope of this research, 1. Predict the level of workplace accidents. 2. Criteria for the cause of work accidents 3. Using the Mamdani method and implementing it using. The benefits of research reduce the risk of workplace accidents.
\end{abstract}

Keywords: Fuzzy Logic, Mamdani, Defuzzification Method

\section{Pendahuluan}

Pada Tahun ini banyak terjadi kecelakaan kerja pada PT galang kapal, Hal ini disebabkan oleh kelalaian manusia serta alat keselamatan yang kurang lengkap. Setiap perusahaan harus memiliki kelengkapan alat agar karyawan tidak mengalami kecelakaan seperti luka fisik maupun kehilangan nyawa. Dengan menggunakan alat pengaman yang lengkap, mengikuti aturan yang sesui dengan ketentuan serta teknik yang bagus akan terhindar dari kecelakaan kerja. Sehinnga keselamatan karyawan terjamin. Karyawan akan lebih tenang bekerja jika di lengkapi dengan paralatan yang lengkap. Permasalahan yang terjadi pada saat ini adalah kurang nya keselamatan kerja pada para pekerja industry sehingga sering terjadi kecelakaan kerja yang mengakibatkan kerusakan fisik dan nyawa bagi para pekerja, kecelakaan kerja pada PT galang kapal terdapat pada Koran tribun dan berita internet Batam, Seperti meninggal karena kepala atas remuk setelah tertimpa besi, Wajah meleleh terkena minyak 
panas kapal, terbakar dalam kapal serta tertimba besi yang menyebabkan kamatian. Hal ini disebabkan oleh kelalaian dan kesadaran pekerja dalam Untuk menjaga keselamatan bagi Karyawan serta peralatan yang dipersiapkan perusaahaan dalam kenyamanan bekerja. Untuk menjaga keselamatan perusahaan dan karyawan harus memahami cara cara pemakaian alat yang aman agar tidak terjadi kecelakaan saya bekerja. Maka penelitian ini menggunkan sebuah metode mamdani fuzzy untuk membantu karyawan dalam mengantisipasi kecelakaan dalam bekerja pada PT galang kapal.

Logika Fuzzy adalah Sebuah system Pemecahan masalah yang cocok dalam sebuah system. Dimulai dari hal yang kecil,sederhana dan penyebaran nya secara luas. Bisa dijadikan acuan dalam pemecahan masalah untuk mengambil sebuah keputusan[1]. Dalam logika klasik dinyatakan bahwa segala sesuatu bersifat biner, yang artinya adalah hanya mempunyai dua kemungkinan, "Ya atau Tidak", "Benar atau Salah", "Baik atau Buruk", dan lain lain. Oleh karena itu, semua ini dapat mempunyai nilai keanggotaan 0 atau 1.Akan tetapi, dalam logika fuzzy memungkinkan nilai keanggotaan berada di antara 0 dan 1. Artinya, bisa saja suatu keadaan mempunyai dua nilai "Ya dan Tidak", "Benar dan Salah", "Baik dan Buruk" secara bersamaan, namun besar nilainya tergantung pada bobot keanggotaan yang dimilikinya Logika Fuzzy menyediakan cara sederhana untuk sampai pada suatu kesimpulan yang pasti berdasarkan kabur ,ambigu, tidak tepat, berisik, atau hilang informasi masukan . logika Fuzzy dimulai dengan konsep himpunan Fuzzy [2].

Profesor L. A. Zadeh merupakan seorang ilmuan yang menemukan ilmu logika fuzzy Beberapa alasan mengapa orang menggunakan logika Fuzzy [3].

, antara lain:

1. Konsep yang digunakan dalam logika fuzzy mudah dimengerti.

2. Fuzzy sangat fleksisbel,

3. Fuzzy mempunyai tolerasi terhadap data yang ada

4. Logika fuzzy dapat membangun dan mengaplikasikan pengalaman-pengalaman para pakar secara langsung tanpa harus melalui proses pelatihan.

5. Logika fuzzy menggunakan bahasa alami, sehingga mudah di pahami dalam kehidupan sehari hari.

Dalam pembuatan fuzzy diperlukan pemahaman tentang konsep logika fuzzy [4].

a. Variabel Fuzzy

Variabel yang akan dibahas pada Fuzzy

b. Himpunan Fuzzy

Suatu group yang mewakili suatu kondisi atau keadaan tertentu dalam suatu variabel Fuzzy.

Sebuah grup yang mewakili sebuah variabel fuzzy

c. Semesta pembicaraan

Suatu nilai yang boleh digunakan dalam fuzzy

d. Domain

Semua nilai yang boleh gunakan dalam semesta pembicaraan fuzzy

Fuzzy Rule-Based Systems (FRBSs) bahasa linguistic dengan menggunakan Fuzzy Inference System metode Mamdani[5]. Hasil dari penelitian ini membuktikan kegunaan dari FRBSs bahasa linguistic dalam sebuah perkembangan dan masalah signifikan dalam data mining seperti klasifikasi dataset yang tidak seimbang dan khusus untuk mereka dengan tingkat ketidakseimbangan yang tinggi. Pendekatan yang diusulkan juga diterapkan pada kumpulan data Urban Masyhad yang sebenarnya untuk menggambarkan kemampuan FSLIM dalam menemukan pengetahuan tersembunyi yang tidak dapat diekstraksi dengan metode tradisional[6]. 
Himpunan fuzzy memiliki dua atribut yaitu:

a. Linguistik, yaitu nama suatu kelompok yang mewakili suatu keadaan tertentu dengan menggunakan bahasa alami, misalnya DINGIN, SEJUK, PANAS mewakili variabel temperatur.

b. Numeris, yaitu suatu nilai yang menunjukkan ukuran dari suatu variabel, misalnya 10 , 35,40 , dan sebagainya[7].

Himpunan adalah suatu kumpulan ataukoleksi objek-objek yang mempunyai kesamaan sifat tertentu.Himpunan fuzzy merupakan suatu pengembangan lebih lanjut tentang konsep himpunan dalam matematika. Himpunan fuzzy adalah rentang nilai-nilai, masing-masing nilai mempunyai derajat keanggotaan antara 0 sampai dengan [8]. Pada himpunan tegas (crisp), nilai keanggotaan suatu intem $\mathrm{x}$ dalam suatu himpunan $\mathrm{A}$, yang sering ditulis dengan $\mu \mathrm{A}[\mathrm{x}]$ memiliki dua kemungkinan, yaitu[9]:

1. Satu (1), yang berarti bahwa suatu intem menjadi anggota dalam satu himpunan.

2. Nol (0) yang berarti bahwa suatu intem tidak menjadi anggota dalam suatu himpunan

Sistem inferensi fuzzy merupakan proses pengolahan data dalam bentuk crisp input yang melalui beberapa tahapan dalam sistem fuzzy untuk menghasilkan data dalam bentuk crips output [10]. Sistem inferensi fuzzy yang harus dilalui, yaitu:

1. Nilai Input.

Berupa masukan dalam bentuk nilai pasti (crisp).

2. Komposisi Fuzzy.

3. Aturan-aturan (rules)

4. Dekomposisi Fuzzy

5. Nilai Output

\section{Metode Penelitian}

Desain penelitian merupakan sebuah langkah untuk mendaptkan gambaran informasi yang berhubungan dengan keselamatan kerja dalam sebuah perusahaan. Dari pengamatan awal di dapatkan hipotesis untuk memecahkan masalah yang perlu dipecahkan seperti yang telah disinggung secara garis besar pada bab pendahuluan. Masalah - masalah tersebut adalah :

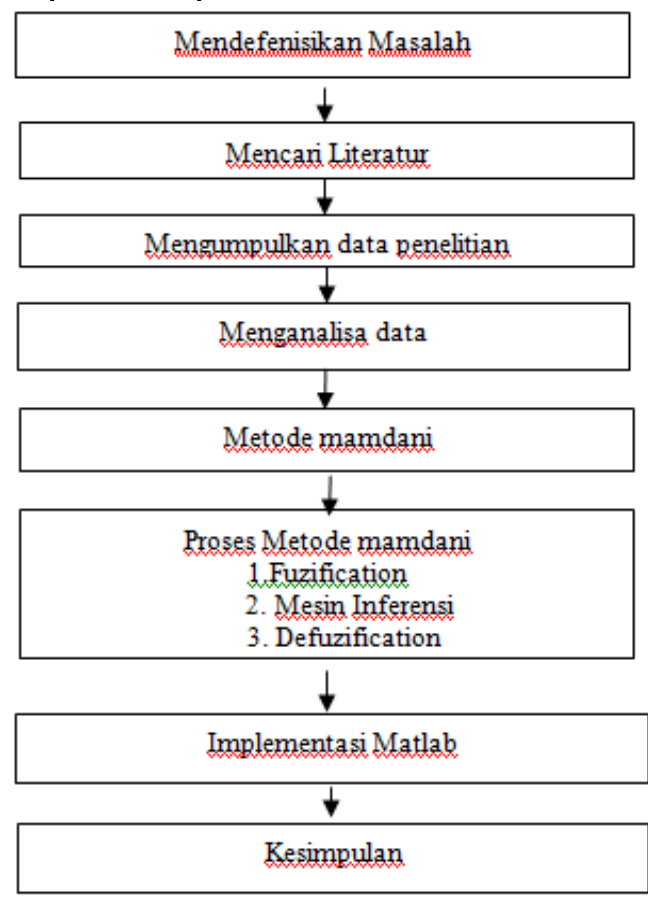

Gambar 1. Desain Penelitian 


\section{Hasil Dan pembahasan}

Berikut bentuk analisis data yang akan dilakukan dalam penelitian ini.

Tabel 1. Analisis Data

\begin{tabular}{|r|l|l|}
\hline Input & Proses & Keputusan \\
\cline { 1 - 1 } a. Alat Pengaman & & \\
\cline { 1 - 1 } b. Aturan/Prosedur & \multirow{2}{*}{ Mamdani } & Tingkat Keselamatan \\
\cline { 1 - 1 } c. Lokasi & & \\
\hline d. Teknik & & \\
\hline
\end{tabular}

Data pada domain fuzzy diperoleh dari PT galang kapal sesuai dengan analisa data yang dilakukan

Tabel 2. Domain Himpunan Fuzzy

\begin{tabular}{|c|c|c|c|}
\hline Variabel & Nama Himpunan Fuzzy & Domain & Semesta Pembicaraan \\
\hline \multirow{3}{*}{ Alat Pengaman } & Sangat Bagus & [70 100] & {$\left[\begin{array}{llll}70 & 90 & 100\end{array}\right]$} \\
\hline & Bagus & {$\left[\begin{array}{ll}40 & 80\end{array}\right]$} & {$\left[\begin{array}{llll}40 & 60 & 80\end{array}\right]$} \\
\hline & Tidak Bagus & {$\left[\begin{array}{ll}0 & 50\end{array}\right]$} & {$\left[\begin{array}{lll}0 & 30 & 50\end{array}\right]$} \\
\hline \multirow{3}{*}{ Aturan/ Prosedur } & Sangat disiplin & {$\left[\begin{array}{ll}65 & 100\end{array}\right]$} & {$\left[\begin{array}{ll}65 & 100\end{array}\right]$} \\
\hline & Disiplin & {$\left[\begin{array}{ll}55 & 80\end{array}\right]$} & {$\left[\begin{array}{ll}55 & 80\end{array}\right]$} \\
\hline & Tidak Disiplin & [0 65] & {$\left[\begin{array}{ll}0 & 65\end{array}\right]$} \\
\hline \multirow{3}{*}{ Lokasi } & Sangat Strategis & {$\left[\begin{array}{ll}75 & 100\end{array}\right]$} & {$\left[\begin{array}{ll}75 & 100\end{array}\right]$} \\
\hline & Strategis & {$\left[\begin{array}{ll}60 & 85\end{array}\right]$} & {$\left[\begin{array}{ll}60 & 85\end{array}\right]$} \\
\hline & Tidak Strategis & {$[075]$} & {$[075]$} \\
\hline \multirow[t]{2}{*}{ Teknik } & Banyak & [0 45] & 03545 \\
\hline & Sedang & {$\left[\begin{array}{ll}35 & 75\end{array}\right]$} & 354575 \\
\hline \multirow{4}{*}{$\begin{array}{l}\text { Tingkat Keselamatan } \\
\text { Kerja }\end{array}$} & Sedikit & {$\left[\begin{array}{ll}55 & 100\end{array}\right]$} & 5575100 \\
\hline & Besar & [0 40] & {$\left[\begin{array}{lll}0 & 40 & 60\end{array}\right]$} \\
\hline & Sedang & {$\left[\begin{array}{ll}50 & 80\end{array}\right]$} & {$\left[\begin{array}{lll}50 & 70 & 80\end{array}\right]$} \\
\hline & Kecil & {$\left[\begin{array}{lll}75 & 100\end{array}\right]$} & {$\left[\begin{array}{llll}75 & 80 & 100\end{array}\right]$} \\
\hline
\end{tabular}

\section{Analisa Sistem untuk Variabel Alat Pengaman}

Nilai variabel Alat Pengaman dibagi atas 3 penilai seperti table Dibawah

Tabel 3. Himpunan Fuzzy Variabel Alat Pengaman

\begin{tabular}{|c|c|c|c|c|}
\hline $\begin{array}{l}\text { Semesta } \\
\text { Pembicaraan }\end{array}$ & Nama himpunan fuzzy & Model MF & Parameter & Domain \\
\hline $0-100$ & Sangat Bagus & Trimf & {$\left[\begin{array}{llll}70 & 90 & 100\end{array}\right]$} & [70 100] \\
\hline $0-100$ & Bagus & Trimf & {$\left[\begin{array}{llll}40 & 60 & 80\end{array}\right]$} & {$\left[\begin{array}{ll}40 & 80\end{array}\right]$} \\
\hline $0-100$ & Tidak Bagus & Trimf & {$\left[\begin{array}{llll}0 & 30 & 50\end{array}\right]$} & {$\left[\begin{array}{ll}0 & 50\end{array}\right]$} \\
\hline
\end{tabular}

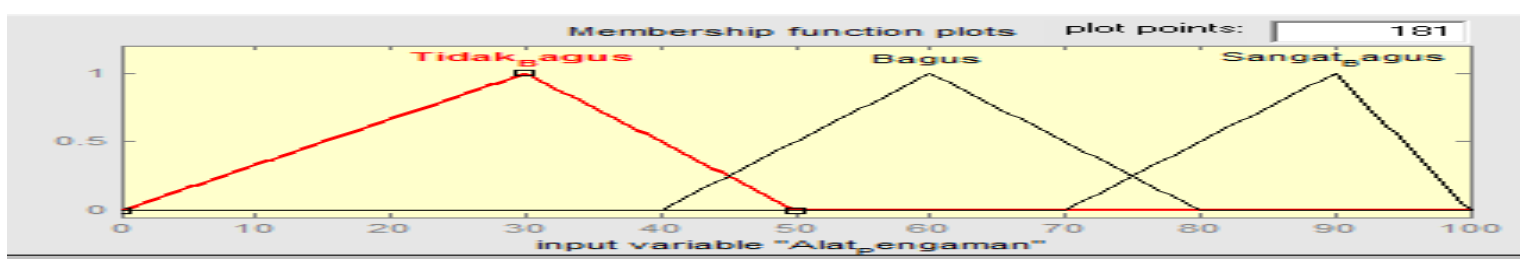

Gambar 2. Fungsi Derajat Keanggotaan Alat Pengamanan 
Berikut adalah pembentukan himpunan fuzzy Alat Pengaman:

$\mu$ Tidak Bagus $[\mathrm{x}]=\left\{\begin{array}{cr}1 ; & x \leq 30 \\ \frac{50-\mathrm{x}}{50-30} ; & 30 \leq \mathrm{x} \leq 50 \\ 0 ; & \mathrm{x} \geq 50\end{array}\right.$

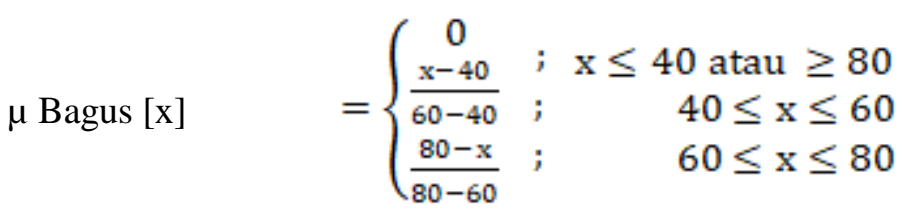

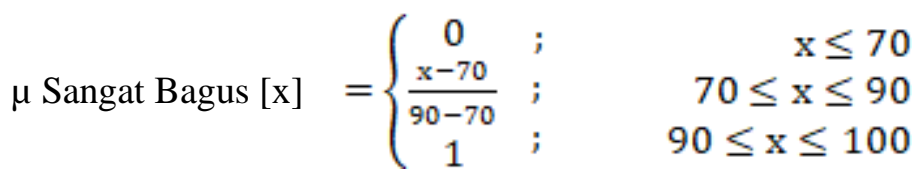

Nilai diatas adalah pembentukan himpunan fuzzy. Nilai tersebut diperoleh dari persamaan linear pada data input Alat pengaman yang terdapat pada table 2 .

\section{Analisa Sistem untuk Variabel Prosedur}

Nilai variabel prosedur dibagi atas 3 penilai seperti tabel

Tabel 4. Himpunan Fuzzy Variabel prosedur

\begin{tabular}{|c|c|c|c|c|}
\hline $\begin{array}{l}\text { Semesta } \\
\text { Pembicaraan }\end{array}$ & $\begin{array}{l}\text { Nama himpunan } \\
\text { fuzzy }\end{array}$ & Model MF & Parameter & Domain \\
\hline $0-100$ & Sangat Disiplin & Trimf & {$\left[\begin{array}{lll}75 & 85 & 100\end{array}\right]$} & {$\left[\begin{array}{ll}75 & 100\end{array}\right]$} \\
\hline $0-100$ & Disiplin & Trimf & [ $\left.\begin{array}{lll}60 & 75 & 85\end{array}\right]$ & {$\left[\begin{array}{ll}60 & 85\end{array}\right]$} \\
\hline $0-100$ & Tidak Disiplin & Trimf & {$\left[\begin{array}{lll}0 & 60 & 75\end{array}\right]$} & {$[075]$} \\
\hline
\end{tabular}

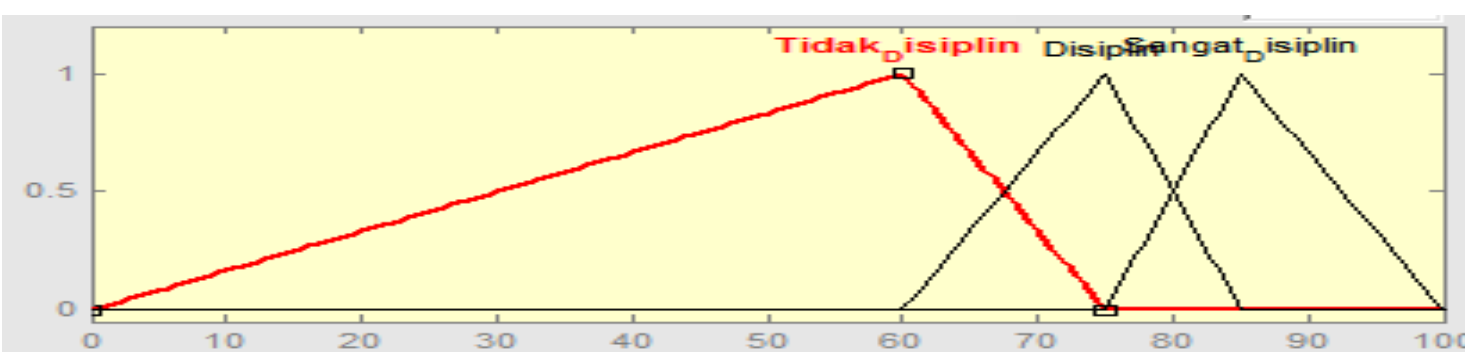

Gambar 3. Fungsi Derajat Keanggotaan Alat Prosedur

Bentuk perhitungan Prosedur secara manual :

$\mu$ Tidak Disiplin $=\left\{\begin{array}{lc}1 ; & x \leq 60 \\ (75-x) /(75-60) & 60 \leq x \leq 75 \\ 0 ; & x \geq 75\end{array}\right.$

$\mu$ Disiplin $=$

$$
\begin{cases}0 ; & x \leq 60 \text { atau } x \geq 85 \\ (x-60) /(75-60) ; & 60 \leq x \leq 75 \\ (85-x) /(85-75) ; & 75 \leq x \leq 85\end{cases}
$$


$\mu$ Sangat Disiplin $=$

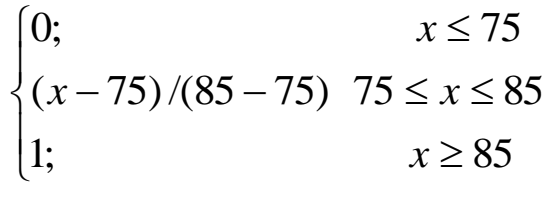

Nilai diatas adalah pembentukan himpunan fuzzy. Nilai tersebut diperoleh dari persamaan linear pada data input Prosedur yang terdapat pada table 2.

\section{Analisa Sistem untuk Variabel Lokasi}

Nilai variabel Lokasi dibagi atas 3 penilai seperti tabel

Tabel 5. Himpunan Fuzzy Variabel Lokasi

\begin{tabular}{|c|c|c|c|c|}
\hline $\begin{array}{l}\text { Semesta } \\
\text { Pembicaraan }\end{array}$ & $\begin{array}{l}\text { Nama himpunan } \\
\text { fuzzy }\end{array}$ & Model MF & Parameter & Domain \\
\hline $0-100$ & Strategis & Trimf & {$\left[\begin{array}{llll}65 & 80 & 100\end{array}\right]$} & {$\left[\begin{array}{ll}65 & 100\end{array}\right]$} \\
\hline $0-100$ & Cukup Strategis & Trimf & {$\left[\begin{array}{llll}5 & 5 & 65 & 80\end{array}\right]$} & [55 80] \\
\hline $0-100$ & Tidak Strategis & Trimf & {$\left[\begin{array}{lll}0 & 55 & 65\end{array}\right]$} & {$\left[\begin{array}{ll}0 & 65\end{array}\right]$} \\
\hline
\end{tabular}

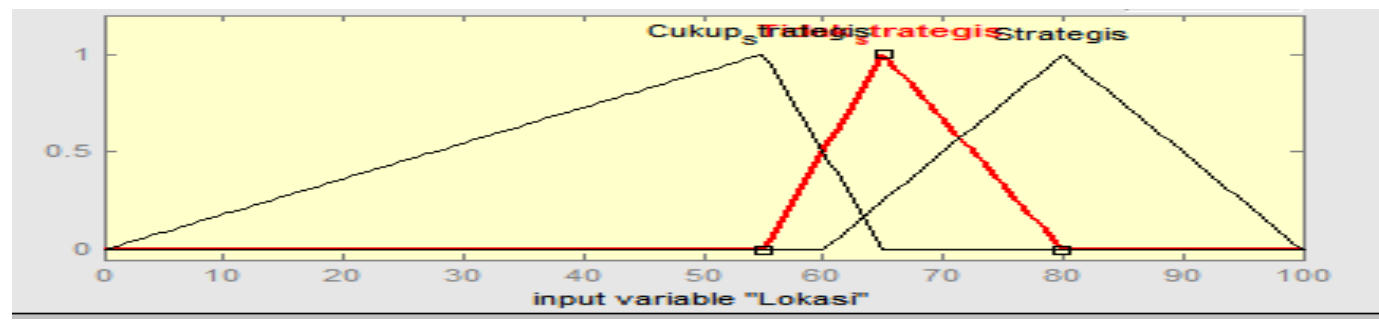

Gambar 4. Membership Function Variabel Lokasi

$\mu$ Tidak strategis
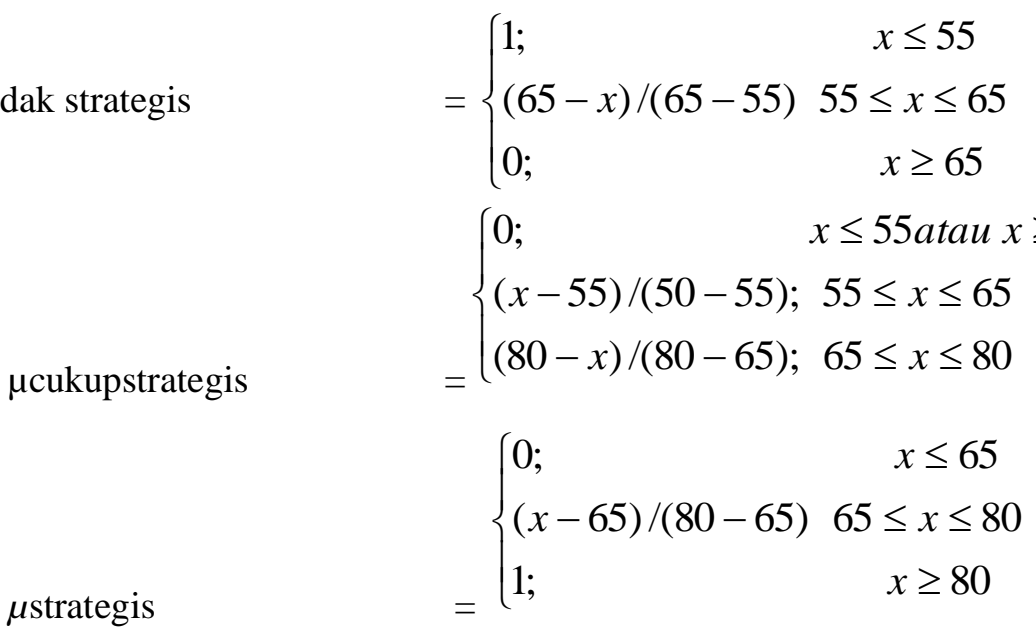

Nilai diatas adalah pembentukan himpunan fuzzy. Nilai tersebut diperoleh dari persamaan linear pada data input Lokasi yang terdapat pada table 2. 


\section{Analisa Sistem untuk Variabel Teknik}

Nilai variabel Teknik dibagi atas 3 penilai seperti tabel

Tabel 6. Himpunan Fuzzy Variabel Teknik

\begin{tabular}{|c|c|c|c|c|}
\hline $\begin{array}{l}\text { Semesta } \\
\text { Pembicaraan }\end{array}$ & $\begin{array}{l}\text { Nama } \\
\text { himpunan } \\
\text { fuzzy }\end{array}$ & Model MF & Parameter & Domain \\
\hline $0-100$ & Banyak & Trimf & {$\left[\begin{array}{ll}0 & 45]\end{array}\right.$} & 03545 \\
\hline $0-100$ & Sedang & Trimf & {$\left[\begin{array}{ll}35 & 75\end{array}\right]$} & 354575 \\
\hline $0-100$ & Sedikit & Trimf & {$\left[\begin{array}{lll}55 & 100\end{array}\right]$} & 5575100 \\
\hline
\end{tabular}
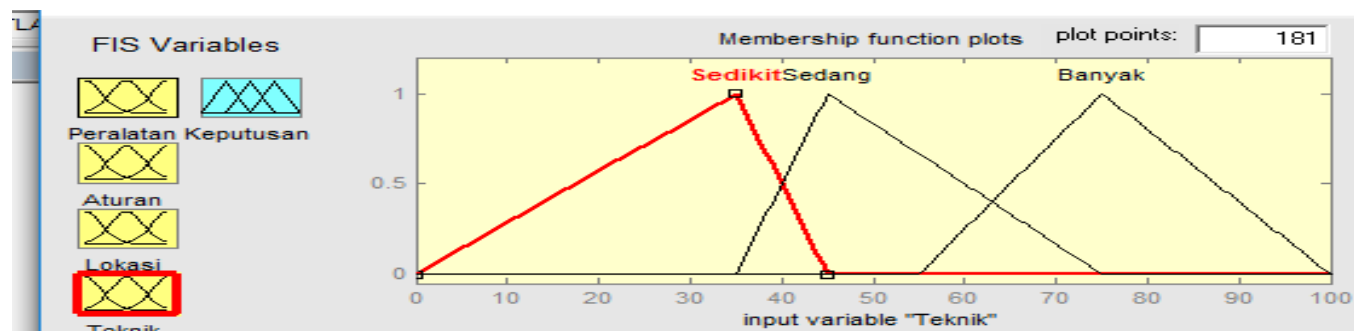

Gambar 5. Membership Function Variabel Teknik

$\mu$ Banyak $[\mathrm{x}]=\left\{\begin{array}{cc}1 ; & \mathrm{x} \leq 30 \\ \frac{100-\mathrm{x} ;}{45-30} ; & 45 \leq \mathrm{x} \leq 100 \\ 0 ; & \mathrm{x} \geq 100\end{array}\right.$
$\mu$ Sedang $[\mathrm{x}]=\left\{\begin{array}{cc}0 & ; \mathrm{x} \leq 30 \text { atau } \geq 700 \\ \frac{\mathrm{x}-30}{45-30} ; & 30 \leq \mathrm{x} \leq 70 \\ \frac{70-\mathrm{x}}{70-45} ; & 45 \leq \mathrm{x} \leq 70\end{array}\right.$

$\mu$ Sedikit $[\mathrm{x}]=\left\{\begin{array}{ccc}0 & \mathrm{x} \leq 55 \\ \mathrm{x}-55 & ; & 55 \leq \mathrm{x} \leq 75 \\ 55-75 ; & 75 \leq \mathrm{x} \leq 100\end{array}\right.$

Nilai diatas adalah pembentukan himpunan fuzzy. Nilai tersebut diperoleh dari persamaan linear pada data input Teknik yang terdapat pada table 2 .

\section{Analisa Sistem untuk Variabel Keputusan}

Nilai variable lKeputusan dibagi atas 3 penilai seperti tabel

Tabel 7. Himpunan Fuzzy Variabel Keputusan

\begin{tabular}{|l|l|l|l|l|}
\hline $\begin{array}{c}\text { Semesta } \\
\text { Pembicaraan }\end{array}$ & $\begin{array}{l}\text { Nama himpunan } \\
\text { fuzzy }\end{array}$ & Model MF & Parameter & Domain \\
\hline $0-100$ & Besar & Trimf & {$\left[\begin{array}{ll}0 & 60\end{array}\right]$} & {$\left[\begin{array}{lll}0 & 40 & 60\end{array}\right]$} \\
\hline $0-100$ & Sedang & Trimf & {$\left[\begin{array}{lll}50 & 80\end{array}\right]$} & {$\left[\begin{array}{lll}50 & 70 & 80\end{array}\right]$} \\
\hline $0-100$ & Kecil & Trimf & {$\left[\begin{array}{lll}75 & 100\end{array}\right]$} & {$\left[\begin{array}{lll}75 & 80 & 100\end{array}\right]$} \\
\hline
\end{tabular}




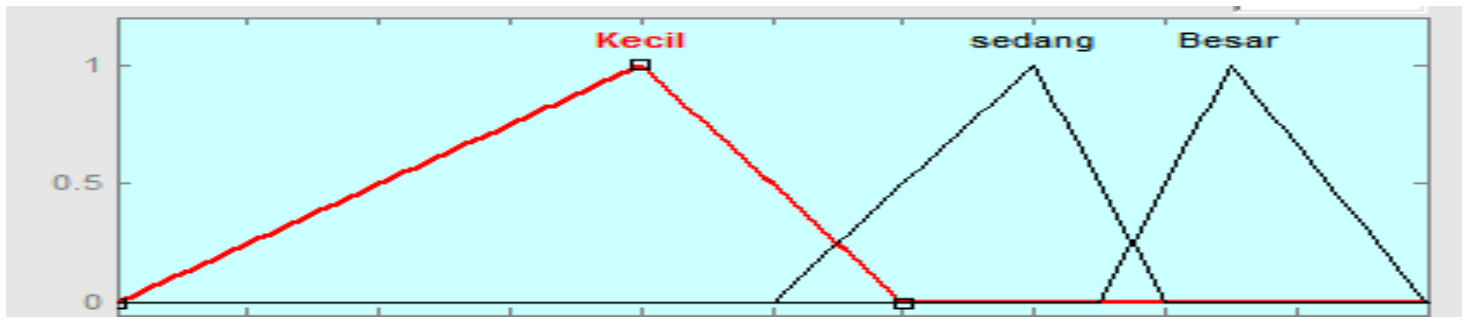

Gambar 6. Representasi Variabel Keputusan

Pada metode mamdani menggunakan fungsi implikasi dengan mengambil nilai min terendah dalam proses pengujian data. Tapi, sebelum masuk ke fungsi implikasi, ditentukan rule-nya terlebih dahulu. Rule di dapatkan dari pernyataan kombinasi data yang ditulis dalam bentuk if then. Sehinggga mudah untuk dimengerti. Bentuk kombinasi rule pada dapat dilihat pada proses dibawah ini :

Tabel 8. Pembentukan Rule

\begin{tabular}{|c|c|c|c|c|c|}
\hline \multirow{2}{*}{ No } & \multicolumn{4}{|l|}{ Variabel } & \multirow{2}{*}{$\begin{array}{l}\text { Tingkat } \\
\text { Keselamatan }\end{array}$} \\
\hline & Alat pengaman & Prosedur & Lokasi & Teknik & \\
\hline R1 & Tidak Bagus & $\begin{array}{l}\text { Sangat } \\
\text { Disiplin }\end{array}$ & Tidak Strategis & Sedang & Kecil \\
\hline R2 & Tidak Bagus & $\begin{array}{l}\text { Sangat } \\
\text { Disiplin }\end{array}$ & Tidak Strategis & Banyak & Sedang \\
\hline R3 & Tidak Bagus & $\begin{array}{l}\text { Sangat } \\
\text { Disiplin }\end{array}$ & Strategis & Sedikit & Kecil \\
\hline R4 & Tidak Bagus & $\begin{array}{l}\text { Sangat } \\
\text { Disiplin }\end{array}$ & Strategis & Sedang & Sedang \\
\hline R5 & Tidak Bagus & $\begin{array}{l}\text { Sangat } \\
\text { Disiplin }\end{array}$ & Strategis & Banyak & Sedang \\
\hline R6 & Tidak Bagus & $\begin{array}{l}\text { Sangat } \\
\text { Disiplin }\end{array}$ & $\begin{array}{l}\text { Sangat } \\
\text { Strategis }\end{array}$ & Sedikit & Sedang \\
\hline
\end{tabular}

Pada tabel 8 merupakan rule yang diperoleh dari hasil kombinasi Himpunan fuzzy yang sudah dilakukan proses pencarian data.

\section{Pengujian 1 Pembentukan Himpunan Fuzzy}

Penyelesaian masalah untuk kasus pengambilan keputusan dalam penentuan Tingkat Keselamatan Kerja, adalah sebagai berikut:

Input $:$ Alat Pengamanan $=72 ;$ Prosedur $=60 ;$ Lokasi $=90 ;$ Teknik $=80$.

1. Alat Pengaman, terdiri dari 3 himpunan fuzzy, yaitu Tidak Bagus, Bagus, dan Sangat Bagus. Jika diketahui Alat Pengaman sebesar 72, maka:

$$
\begin{aligned}
\mu \text { Tidak Bagus [72] } & =0 \\
\mu \text { Bagus [72] }=(\mathrm{c}-\mathrm{x}) /(\mathrm{c}-\mathrm{b}) & =(80-72) /(80-60) \\
& =8 / 20 \\
& =0,4 \\
\mu \text { Sangat Bagus [72] } & =(\mathrm{x}-\mathrm{a}) /(\mathrm{b}-\mathrm{a}) \\
& =(72-70) /(90-70) \\
& =2 / 10 \\
& =0,2
\end{aligned}
$$


2. Prosedur, terdiri dari 3 himpunan fuzzy, yaitu sedik, sedang dan banyak. Jika diketahui Prosedur sebesar 60, maka:

$$
\begin{aligned}
\mu \text { Sedang }[60]=(c-x) & /(c-b) \\
& =(70-60) /(70-65) \\
& =10 / 5 \\
& =0,2
\end{aligned}
$$

3. Lokasi, terdiri dari 3 himpunan fuzzy, yaitu Tidak srategi, strategi dan tidak starategis Jika diketahui Lokasi sebesar 90, maka:

$$
\begin{aligned}
\mu \text { Sangat Strategis [90] }=(c-x) / & (c-b) \\
& =(100-90) /(100-80) \\
& =10 / 20 \\
& =0,5
\end{aligned}
$$

4. Teknik, terdiri dari 3 himpunan fuzzy, yaitu Banyak, sedikit, Sedang Jika diketahui Teknik sebesar 80, maka:

$$
\begin{aligned}
\mu \text { Banyak [80] } & =(c-x) /(c-b) \\
& =(100-80) /(100-75) \\
& =20 / 25 \\
& =0,8
\end{aligned}
$$

\section{Aplikasi Fungsi Implikasi}

Langkah selanjutnya yaitu menentukan fungsi implikasi agar mendapatkan nilai akhir fuzzy dari setiap proses rule. Fungsi implikasi menggunakan nilai terendah (min). Rule yang mempunyai nilai derjat keanggotaan adalah sebagai berikut.

[R79] if Alat Pengaman BAGUS, and Prosedur SEDANG, and Lokasi SANGAT STARTEGIS, and Teknik Banyak, then Keselamatan Kerja Tinggi.

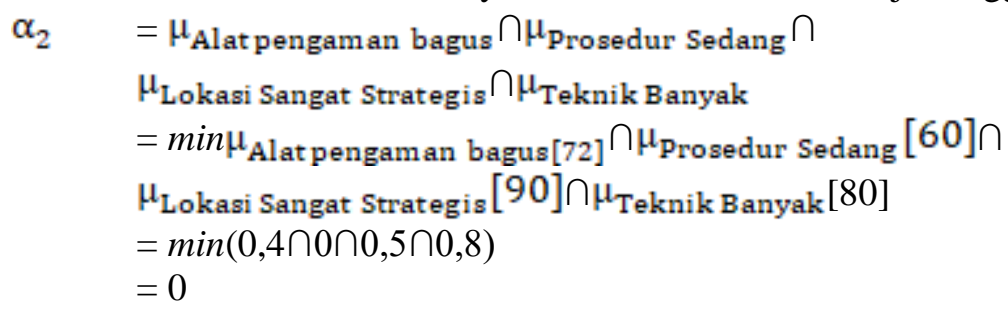

[R81] if Alat Pengaman SANGAT BAGUS, and Prosedur SEDANG, and Lokasi SANGAT STARTEGIS, and Teknik Banyak, then Keselamatan Kerja Tinggi.

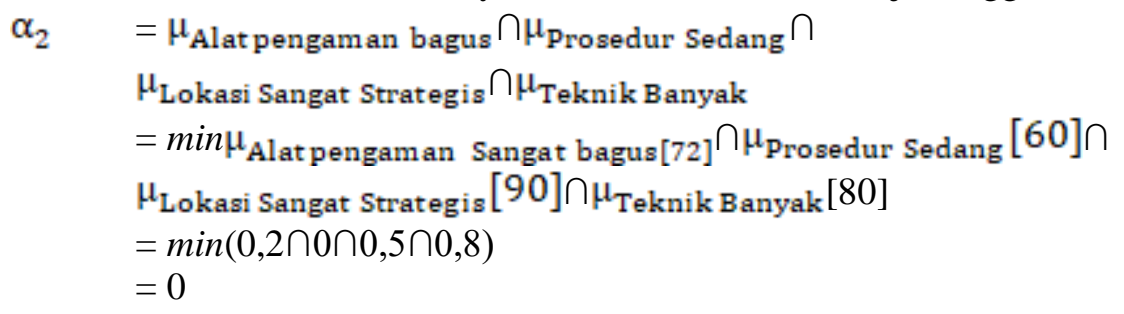

Hasil Defizification Menentukan tingkat keselamatan kerja Pt galang Kapal di Kota Batam :

$$
\begin{array}{ll}
= & (72 * 0.4)+(60 * 0.2)+(60 * 0)+(90 * 0.2)+(90 * 0)(80 * 0.5)+(80 * 0) \\
= & 28.9+12+0+18+0+40+0 \\
= & 98.9 / 1.3 \\
= & 76.07
\end{array}
$$




\section{Pengujian Sistem}

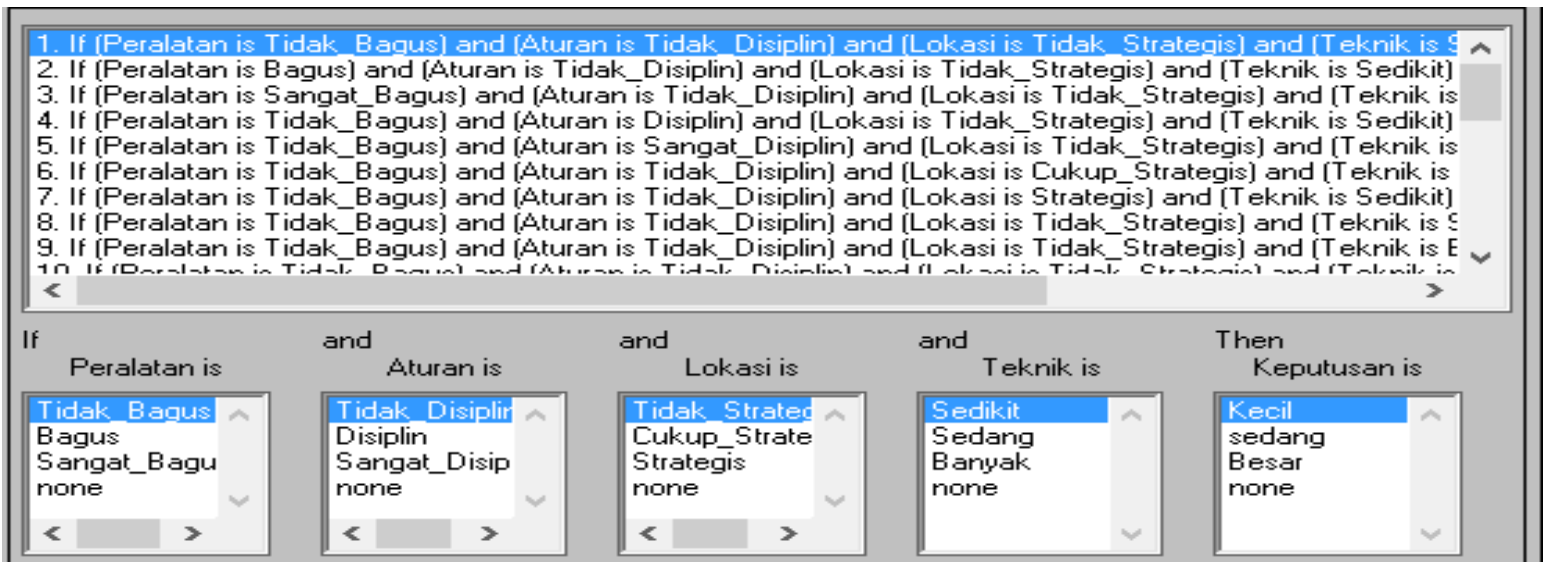

Gambar 7. Tampilan rule Sistem Matlab

Tabel 7 ini merupakan implementasi pada software matlab. Hal yang harus diperhatikan yaitu memcocokkan kombinasi rule pada himpunan fuzzy.

Berikut adalah pengujian pertama dengan Input : Alat Pengamanan $=72$; Prosedur $=60 ;$ Lokasi $=90 ;$ Teknik $=80$.

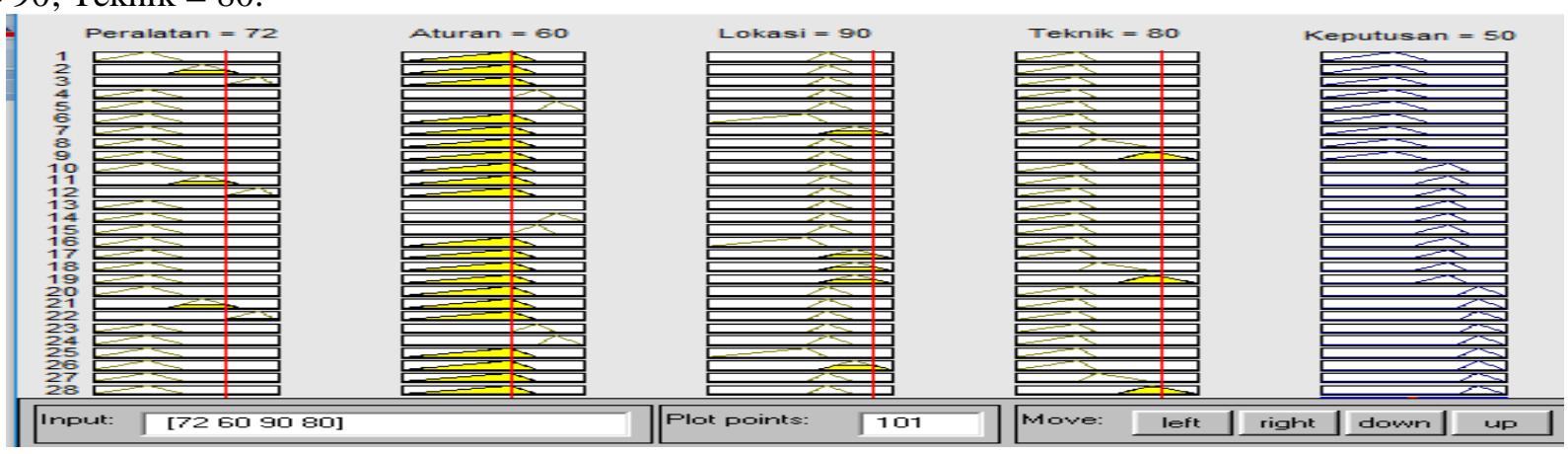

Gambar 8. Tampilan Hasil Pertama Sistem Matlab

Setelah memcocokkan kombinasi rule pada himpunan fuzzy, langkah selanjutnya memasukkan nilai ke setiap input pada software matlab sehinggan menghasilkan output berupa nilai 50 .

\section{Kesimpulan}

Berdasarkan pembahasan penelitian dan analisa yang telah yang dilakukan, maka dapat disimpulkan beberapa hal, yaitu:

1. Dalam menentukan Tingkat keselamatan kerja membutuhkan variabel input dan variabel output. Variabel input terdiri dari Alat pengaman, Prosedur, Lokasi dan Teknik. Sedangkan variabel output Tingkat keselamatan kerja. Hal dapat membantu dalam memprediksi keselamatan kerja karyawan.

2. Fuzzy Logic dengan metode Mamdani dapat membantu memperkecil resiko kecelakaan kerja bagi karyawan galang kapal..

3. Dengan penelitian ini bisa membantu karyawan dalam proses kerja agar bisa mengantisipasi kecelakaan kerja. 


\section{Daftar pustaka}

[1] Minarni, \& Aldyanto, F. (2016). Prediksi Jumlah Produksi Roti Menggunakan Metode Logika Fuzzy. Teknologi Informasi, 4(2), 59-65.

[2] Ak, V. N. O. V. (2016). A NOTE TO INTERPRETABLE FUZZY MODELS AND, 13(7), 53-65.

[3] Kusumadewi Sri dan Hari Purnomo, (2013). Aplikasi Fuzzy Logic Untuk Pendukung Keputusan, Edisi 2, Graha Ilmu, Yogyakarta.

[4] Sutojo, T., Mulyanto Edy. dan Suhartono Vincent, (2011). Kecerdasan Buatan. Edisi 1, Andi Offset, Yogyakarta.

[5] Fernandez, A., \& Herrera, F. (2012). Linguistic Fuzzy Rules in Data Mining : Follow-Up Mamdani Fuzzy Modeling Principle. Combining Experimentation and Theory, 103-122.

[6] Widiyantoro, A., Sutojo, T., \& Sudaryanto. (2014). Menerapkan Logika Fuzzy Mamdani Untuk. Techno.COM, 13(2), 69-74.

[7] Shakiba, A., Hooshmandasl, M. R., Davvaz, B., \& Fazeli, S. A. S. (2017). Sapproximation spaces: a fuzzy approach. Iranian Journal of Fuzzy Systems, 14(2), 127154.

[8] Charolina, Y. (2016). Sistem Pendukung Keputusan Untuk Menentukan Pemberian Bonus Tahunan Menggunakan Metode Fuzzy Logic Tipe Mamdani. Teknologi Informasi, 12(2), 42-53.

[9] Maryaningsih, Siswanto, \& Masterjon. (2013). Metode Logika Fuzzy Tsukamoto Dalam Sistem Pengambilan Keputusan Penerimaan Beasiswa. Media Infotama, 9(1), 140-165.

[10] Pangaribowo, T. (2015). Perancangan Simulasi Kendali Valve Dengan Algoritma Logika Fuzzy Menggunakan Bahasa Visual Basic. Teknologi Elektro, 6(2), 123-135. 